\title{
Marked differences in GPs' diagnosis of pneumonia between Denmark and Spain: a cross-sectional study
}

\author{
*Sarah Friis Christensen1, Lars Christian Jørgensen, Gloria Cordoba1, Carl Llor², \\ Volkert Siersma', Lars Bjerrum ${ }^{1}$
}

Section of General Practice and Research Unit for General Practice, Department of Public Health, University of Copenhagen, Copenhagen, Denmark

2 University Rovira i Virgili, Spanish Society of Family Medicine, Primary Healthcare Centre Jaume I, Tarragona, Spain

Originally received 15th May 2013; resubmitted 10th July 2013; revised 5th October 2013; accepted 6th October 2013; online 18th November 2013

\begin{abstract}
Background: In patients with lower respiratory tract infections (LRTIS) it is a challenge to identify who should be treated with antibiotics. According to international guidelines, antibiotics should be prescribed to patients with suspected pneumonia while acute bronchitis is considered a viral infection and should, generally, not be treated with antibiotics. Overdiagnosis of pneumonia in patients with LRTIs may lead to antibiotic overprescribing.
\end{abstract}

Aims: To investigate the prevalence of presumed pneumonia in patients with LRTI in two countries with different antibiotic prescribing rates (Denmark and Spain) and to compare which symptoms and clinical tests are of most importance for the GP when choosing a diagnosis of pneumonia rather than acute bronchitis.

Methods: A cross-sectional study including GPs from Denmark and Spain was conducted as part of the EU-funded project HAPPY AUDIT. A total of 2,698 patients with LRTI were included.

Results: In Denmark, $47 \%$ of the patients with LRTI were classified with a diagnosis of pneumonia compared with $11 \%$ in Spain. In Spain, fever and a positive x-ray weighted significantly more in the diagnosis of pneumonia than in Denmark. Danish GPs, however, attached more importance to dyspnoea/polypnoea and C-reactive protein levels $>50 \mathrm{mg} / \mathrm{L}$. None of the other typical symptoms of pneumonia had a significant influence.

Conclusions: Our results indicate that GPs' diagnostic criteria for pneumonia differ substantially between Denmark and Spain. The high prevalence of pneumonia among Danish patients with LRTI may indicate overdiagnosis of pneumonia which, in turn, may lead to antibiotic overprescribing.

(C) 2013 Primary Care Respiratory Society UK. All rights reserved.

SF Christensen et al. Prim Care Respir J 2013; 22(4): 454-458

http://dx.doi.org/10.4104/pcrj.2013.00093

Keywords general practice, pneumonia, overdiagnosis, Denmark, Spain, cross-sectional study

\section{See linked editorial by Infantino and Infantino on pg 383}

\section{Introduction}

The main diagnostic challenge for the general practitioner (GP) when facing patients with lower respiratory tract infections (LRTIS) is to identify who should be treated with antibiotics. According to international recommendations on the management of LRTIs, antibiotics should be prescribed to patients with suspected pneumonia while acute bronchitis is considered to be a viral disease and should therefore not be treated with antibiotics. ${ }^{1-3}$

The main factor in the decision about antibiotic treatment is the clinical diagnosis stated by the GP. It is therefore important to know what criteria influence GPs' decisions about diagnoses, which in turn result in predictable therapy choices.

No single symptom or clinical sign is specific for the presence of pneumonia and, based on clinical signs and symptoms, it may be difficult to distinguish between pneumonia and acute bronchitis. Although a normal chest $x$-ray rules out pneumonia with a high degree of certainty, recommendations discourage x-ray examination

\footnotetext{
* Corresponding author: Dr Sarah Friis Christensen, Afdeling for Almen Medicin, Øster Farimagsgade 5, Opgang Q, stuen og 1.sal, Postboks 2099 , 1014 København K, Denmark. Tel: +45 40792181 E-mail: sarah-fc@hotmail.com
} 
in all patients with cough and fever. The costs are unjustifiably high and patients could be exposed to unnecessary radiation. ${ }^{3}$

Thus, in daily practice it is a challenge for the GP to distinguish between pneumonia and acute bronchitis. Uncertainties in the clinical assessment may lead to overdiagnosis of pneumonia and consequently antibiotic overprescribing. Antibiotic overprescribing is an important reason for the rapidly increasing bacterial resistance. ${ }^{4-6}$ Infections caused by resistant bacteria lead to increased mortality, prolonged hospital stay, and increased cost. ${ }^{7}$ A cornerstone of efforts to control antibiotic resistance is to improve the quality of the diagnostic process in patients with LRTIs in order to avoid overdiagnosing pneumonia.

The aim of this study was to investigate the prevalence of presumed pneumonia in patients with LRTIs and to compare the symptoms and clinical tests that were of most importance for the GP when choosing a diagnosis of pneumonia rather than acute bronchitis in two countries with different antibiotic prescribing rates (Denmark and Spain).

\section{Methods}

\section{Design of study}

This cross-sectional study was conducted as part of the EU-funded project Health Alliance for Prudent Prescribing, Yield and Use of Antimicrobial Drugs in the Treatment of Respiratory Tract Infections (HAPPY AUDIT). Details of the project are described in the study protocol. ${ }^{8}$

\section{Study population}

In Denmark, GPs provide care for all patients registered with the practice, irrespective of age. In Spain, GPs only provide care for individuals over 15 years of age; health problems in children are covered by paediatricians. We therefore restricted our analysis to individuals aged over 15 years. A total of 20,655 patients with respiratory tract infections were registered, of whom 2,698 (13.1\%) were diagnosed either with acute bronchitis or pneumonia. Patients with other respiratory tract infections including influenza and acute exacerbation of chronic obstructive pulmonary disease were excluded. The GPs included patients at the first contact due to the actual infection. Inclusion of patients took place during a three-week period in January 2008. Patients were registered using a prospective selfregistration methodology based on a registration chart completed by the GPs according to the Audit Project Odense method. ${ }^{9}$ For each patient the GP registered observed symptoms and signs, presumed diagnosis, and treatment.

\section{Statistical methods}

Descriptive statistics are presented as proportions and medians (interquartile range) as appropriate. A multivariable logistic regression model including the diagnostic criteria (i.e. sign, symptoms, diagnostic tests, demographic characteristics, and number of days with symptoms) was used to identify which of these criteria were associated with the diagnosis of pneumonia. To test whether the odds ratios (OR)s differed between Denmark and Spain, we performed a test of interaction, ${ }^{10}$ a $t$ test on the difference between the log (OR)s. The data were analysed using Statistical Analysis Software (SAS) Version 9.2.

\section{Results}

In Denmark, $47 \%$ of the patients with LRTIs were classified with the diagnosis of pneumonia compared with $11 \%$ in Spain (Table 1). The baseline characteristics of the patients with pneumonia in the two countries are shown in Table 2 . In both countries the majority were women; the median age in Denmark was 56 years compared with 58 years in Spain. The median number of days with symptoms before the first contact was lower in Spain than in Denmark (4 days vs. 7 days).

Figure 1 shows the distribution of symptoms in patients with pneumonia in Denmark and Spain. Symptoms that indicated a serious infection such as fever, dyspnoea, polypnoea, increased or purulent sputum were most frequently found in patients from Spain. On the other hand, symptoms indicating a viral aetiology such as cough and/or rhinorrhoea were more frequently found in Danish patients.

GPs in Denmark used the point of care test C-reactive protein (CRP) as support for the diagnosis of pneumonia in the majority of patients with suspected LRTI. A high CRP (>50mg/L) was found in $67 \%$ of patients with pneumonia in Denmark. In Spain the CRP test was almost never used. In contrast, GPs in Spain used x-rays as a support for the diagnosis of pneumonia and $61 \%$ of Spanish patients with pneumonia had a positive $\mathrm{x}$-ray.

Table 3 shows the factors associated with the diagnosis of pneumonia. In both countries fever was an important symptom with an OR of 3.1 in Denmark and 5.4 in Spain. Symptoms such as cough, rhinorrhoea, sputum colour, or duration of symptoms were not significantly associated with the diagnosis of pneumonia in either country. In Denmark a high CRP (>50mg/L) was positively associated with the diagnosis (OR 2.4) while a CRP level $<9 \mathrm{mg} / \mathrm{L}$ was negatively associated with a diagnosis of pneumonia. In Spain a positive $x$-ray was of great influence in the diagnosis of pneumonia (OR 1,589.2).

Table 1. Proportion of pneumonia and acute bronchitis in patients with lower respiratory tract infections in Denmark and Spain (95\% confidence interval)

\begin{tabular}{lll} 
Diagnosis & Denmark $(n=518)$ & Spain $(n=2180)$ \\
\hline Pneumonia & $47 \%(42 \%$ to $51 \%)$ & $11 \%(10 \%$ to $12 \%)$ \\
\hline Acute bronchitis & $53 \%(49 \%$ to $58 \%)$ & $89 \%(88 \%$ to $90 \%)$
\end{tabular}

Table 2. Baseline characteristics of the Danish and Spanish patients with pneumonia

\begin{tabular}{lll} 
& Denmark $(\mathrm{n}=241)$ & Spain $(\mathrm{n}=234)$ \\
\hline Median age (IQR) & $56(38-68)$ & $58(43-73)$ \\
\hline $\begin{array}{l}\text { Percentage of women } \\
(95 \% \mathrm{Cl})\end{array}$ & $60 \%(56 \%$ to $64 \%)$ & $58 \%(56 \%$ to $60 \%)$ \\
\hline $\begin{array}{l}\text { Median no. of days } \\
\text { with symptoms (IQR) }\end{array}$ & $7(3-11)$ & $4(2-7)$ \\
\hline $\begin{array}{l}\text { Cl=confidence interval, IQR=interquartile range. } \\
\end{array}$
\end{tabular}


Figure 1. Prevalence ( $95 \%$ confidence interval) of symptoms among patients with pneumonia in general practices in Denmark (DK) and Spain (ESP)

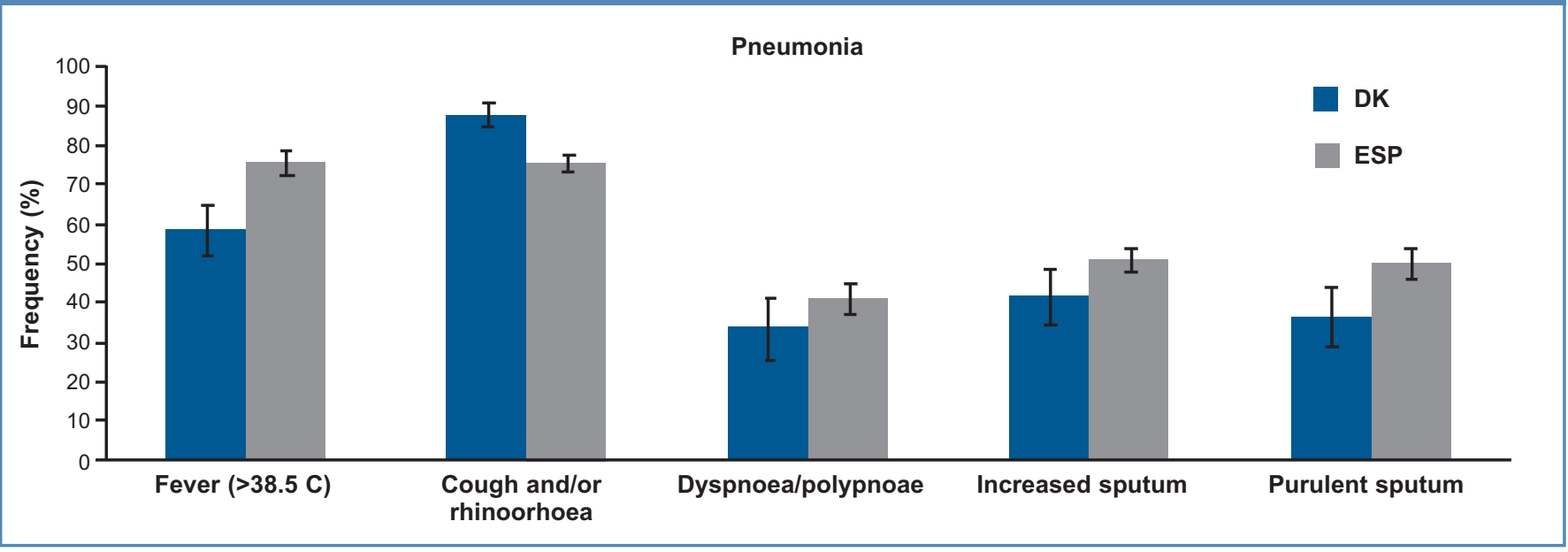

Table 3. Multivariable logistic regression analysis of the factors of influence when diagnosing pneumonia $(95 \%$ confidence interval). The $p$ values show whether the odds ratios are significantly different between Denmark and Spain

\begin{tabular}{|c|c|c|c|}
\hline \multirow[t]{2}{*}{ Predictors } & \multicolumn{2}{|c|}{$\begin{array}{l}\text { Odds ratio } \\
\text { (reference acute bronchitis) }\end{array}$} & \multirow[t]{2}{*}{$\mathrm{p}$ value } \\
\hline & Denmark & Spain & \\
\hline \multicolumn{4}{|l|}{ Age (reference $<31$ years) } \\
\hline $31-60$ & 0.7 (0.4 to 1.1$)$ & $1.0(0.6$ to 1.8$)$ & 0.31 \\
\hline $61+$ & 0.7 (0.3 to 1.6$)$ & $0.6(0.2$ to 1.7$)$ & 0.88 \\
\hline Gender (reference male) & 0.7 (0.4 to 1.2$)$ & 0.7 (0.4 to 1.1$)$ & 0.91 \\
\hline \multicolumn{4}{|c|}{ Duration of symptoms (reference $<4$ days) } \\
\hline 4-7days & 0.7 (0.4 to 1.3$)$ & 1.1 (0.6 to 2.0$)$ & 0.35 \\
\hline$>8$ days & $1.3(0.7$ to 2.4$)$ & $1.4(0.7$ to 3.1$)$ & 0.81 \\
\hline Fever $\left(38.5^{\circ} \mathrm{C}\right)$ & $3.1(1.9$ to 5.2$)$ & 5.4 (3.0 to 9.9$)$ & $<0.001$ \\
\hline Cough and/or rhinorrhoea & 1.2 (0.5 to 3.3 ) & $0.9(0.4$ to 1.9$)$ & 0.51 \\
\hline Dyspnoea/polypnoea & 2.7 (1.5 to 4.7$)$ & $0.9(0.5$ to 1.7$)$ & $<0.001$ \\
\hline Increased sputum & 1.7 (1.0 to 2.9$)$ & $1.3(0.7$ to 2.3$)$ & 0.46 \\
\hline Purulent sputum & 1.3 (0.7 to 2.2$)$ & $1.4(0.8$ to 2.4$)$ & 0.97 \\
\hline \multicolumn{4}{|c|}{ CRP (reference not performed) } \\
\hline$C R P<9 m g / L$ & $0.2(0.1$ to 0.4$)$ & - & N/A \\
\hline CRP $10-49 \mathrm{mg} / \mathrm{L}$ & $0.5(0.3$ to 1.1$)$ & - & N/A \\
\hline $\mathrm{CRP}>50 \mathrm{mg} / \mathrm{L}$ & $2.4(1.3$ to 4.4$)$ & - & N/A \\
\hline \multicolumn{4}{|c|}{ X-ray (reference not performed) } \\
\hline \multirow[t]{2}{*}{ Positive } & $2.7(0.2$ to 36.3$)$ & $1,589.2$ & 0.001 \\
\hline & & (566.9 to $4,455.0$ ) & \\
\hline Negative & 0.2 (0.0 to 2.9 ) & 2.5 (1.0 to 6.0$)$ & 0.065 \\
\hline
\end{tabular}

The calculated $p$ values showed that ORs for fever, dyspnoea/polypnoea, CRP, and a positive x-ray were markedly different between Denmark and Spain.

\section{Discussion}

\section{Main findings}

We found that almost half of Danish patients with LRTIs were classified with a diagnosis of pneumonia compared with only $11 \%$ of patients with LRTIs from Spain.

Symptoms indicating a severe bacterial disease were found less frequently in Danish patients with pneumonia than in Spanish patients. On the other hand, symptoms indicating a viral infection were more frequently found in Danish patients.

In both countries fever was the most important symptom for diagnosing pneumonia. In Denmark, there was a significantly increased OR for dyspnoea/polypnoea - another known symptom of pneumonia. ${ }^{2,11,12}$ None of the other symptoms were significant predictors of pneumonia in Spain or in Denmark. In Denmark a high CRP level was a significant predictor of pneumonia while in Spain a positive $\mathrm{x}$-ray was of most importance in the diagnosis of pneumonia. The ORs for fever, dyspnoea/polypnoea, CRP, and a positive x-ray were markedly different between Denmark and Spain.

\section{Strengths and limitations of the study}

GPs participated in an audit during a three-week period in January 2008. The collected data might therefore not represent the diagnostic decisions throughout the year. Ideally, there should be one year of enrolment. However, we do not believe that this would have affected the observed difference in the frequency of pneumonia among patients with LRTIs in Denmark and Spain.

The GPs participated in the study on a voluntary basis, and their diagnostic habits may not represent the average diagnostic methods of all GPs. GPs willing to register their diagnoses may have been more interested in quality development and research than GPs in general. Furthermore, they were willing to dedicate sufficient time to complete patient reports without economic incentives. The amount of time the GPs had to spend on this project could be considered to 
be a prominent barrier to participation as GPs might find it difficult to dedicate the time in their daily work. However, earlier studies using the same type of data registration did not find it very timeconsuming. ${ }^{13,14}$

Due to the limited time allocated for the registration process, in practice only the typical signs and symptoms of respiratory tract infections according to the medical literature were recorded. This may lead to some limitations in our assessment of factors important for GPs when diagnosing pneumonia.

Before conducting this study we knew that GPs' behaviour with regard to antibiotic use was different between Denmark and Spain. In theory this intrinsic bias could have had an impact on the methodology and interpretation related to the diagnostic classification of patients with LRTIs. However, against our expectations, we found a much higher prevalence of presumed pneumonia in Denmark than in Spain.

This is a pragmatic study where registration of patients was performed in a real-life practice setting. Patients were not informed about the project prior to consultations. GPs participating in the audit were not allocated extra time for the consultations and they were not able to make significant changes in their practice activities during the three weeks of registration. Thus, they attended the patients in the way they would have done without participating in the study. It is therefore most likely that our results can be extrapolated to other areas and practices with similar settings.

\section{Interpretation of findings in relation to previously published work}

There is no reason to believe that pneumonia occurs more frequently in Denmark than in Spain and, according to international literature, the prevalence of pneumonia in patients with LTRI is between $3 \%$ and $20 \%{ }^{3,15}$ In the Happy Audit study the average prevalence of pneumonia among patients with LRTI was $21 \% .{ }^{16}$ Our results thus indicate a diagnostic misclassification due to overdiagnosis of pneumonia in Danish patients with LRTIs, which has also been found in other studies. ${ }^{17}$

Several factors may be responsible for the differences in the diagnostic classification of patients with LRTIs in Denmark and Spain. It is likely to be both a patient- and a physician-driven phenomenon.

The iatrogenic threshold seems to differ between the two countries as Danish patients were seen three days later than Spanish patients. This may be due to discrepancies in national recommendations, different healthcare systems, different treatment traditions, different culture, or different patient expectations.

Fever was the most important symptom for diagnosing pneumonia. This is consistent with previously conducted research. ${ }^{15}$ Most of the other symptoms were not significant predictors of pneumonia either in Spain or Denmark. This is probably due to the huge overlap between the symptoms of pneumonia and acute bronchitis. $^{18}$

In Denmark the majority of patients in primary care classified with pneumonia were not exposed to a radiological examination before the diagnosis was stated. In most cases the GPs used a CRP point of care test as support for the clinical evaluation to distinguish between acute bronchitis and pneumonia. On the other hand, in Spanish primary care the diagnosis of pneumonia was frequently confirmed by an x-ray examination while CRP testing was not used at all. In previous studies both $x$-ray and CRP testing have been shown to improve the diagnosis of pneumonia. ${ }^{19,20}$ However, CRP testing has a low validity compared with $\mathrm{x}$-ray for the diagnosis of pneumonia, and there is no agreement about where to set the cut-off point in order to distinguish between acute bronchitis and pneumonia. ${ }^{21}$ The diagnostic uncertainty and fear of missing a patient with pneumonia may lead to an overdiagnosis and overtreatment with antibiotics.

The ORs for fever, dyspnoea/polypnoea, CRP, and a positive x-ray were markedly different between Denmark and Spain. Thus, in Spain, fever and a positive x-ray weighted significantly more in the diagnosis of pneumonia than in Denmark. Danish GPs, however, attached more importance to dyspnoea/polypnoea and CRP tests.

Despite a lower proportion of pneumonia in patients with LRTIS, Spain has a high antibiotic consumption. This may be explained by the fact that Spanish GPs prescribe antibiotics for acute bronchitis more often than Danish GPs. In the HAPPY AUDIT study almost $60 \%$ of Spanish patients with acute bronchitis were treated with antibiotics compared with approximately $40 \%$ in Denmark. ${ }^{16}$ Moreover, in Spain it is possible to buy antibiotics without a prescription, which may contribute to a higher consumption of antibiotics in general. However, previous studies have shown that many factors can influence antibiotic prescribing in general practice, including GPs' consultation rates, ${ }^{22}$ patients' expectations regarding antibiotics, overestimation of patients' expectations by the GP, and public knowledge about LRTIs and antibiotics. ${ }^{23-25}$ From a theoretical point of view, the decision to treat should be taken after the diagnosis has been established. In general practice, however, the diagnostic procedures and decision to treat are intricately linked. The GP may decide whether or not to prescribe antibiotics at the same time - or even before - ascribing a specific diagnosis to the patient. After making the decision to prescribe, the GP may thus adjust the diagnosis to fit the decision about treatment, leading to diagnostic misclassification and overdiagnosis of pneumonia. ${ }^{8,26}$

Implications for future research, policy, and practice The high prevalence of pneumonia in Danish patients with LRTI may indicate overdiagnosis of pneumonia which in turn may lead to antibiotic overprescribing. To prevent this potential overdiagnosing and overprescribing of antibiotics, we need valid diagnostic predictors. The clinical interpretation of symptoms related to LRTIs appears to be different between Denmark and Spain. More research is needed to develop internationally agreed prediction rules or clinical tests in order to improve the validity of the diagnostic classification of patients with LRTIs in general practice.

\section{Conclusions}

Our results indicate that GPs' diagnostic criteria for diagnosing pneumonia differ substantially between Denmark and Spain. In both countries fever was an important symptom when the GP stated the diagnosis of pneumonia. Except for fever and dyspnoea/polypnoea, none of the other symptoms were significant predictors of pneumonia. The diagnostic tests CRP and x-ray were important predictors for diagnosing pneumonia in Denmark and Spain, respectively. In Spain, fever and a positive x-ray weighted significantly 
more in the diagnosis of pneumonia than in Denmark. Danish GPs, however, attached more importance to dyspnoea/polypnoea and CRP tests. Thus, the observed prevalences of presumed pneumonia may partly be explained by the use of different diagnostic tests.

Almost half the Danish patients with LRTIs were diagnosed with pneumonia compared with only $11 \%$ of patients with LRTIs in Spain. The high prevalence of pneumonia among Danish patients with LRTI may indicate overdiagnosis of pneumonia, which in turn may lead to antibiotic overprescribing.

\section{Handling editor Anthony D'Urzo Statistical review Gopal Netuveli}

Acknowledgements The authors thank the HAPPY AUDIT study patients and practitioners for their time and cooperation.

Conflicts of interest The authors declare they have no conflicts of interest in relation to this article

Contributorship LB had the original idea and is the guarantor of this study. Drafting of the manuscript: SFC under supervision of LB. GC and VS contributed to the statistical analysis. LCJ, CL, VS and GC contributed to and approved the manuscript.

Funding This study was part of the EU-funded project Health Alliance for Prudent Prescribing, Yield and Use of Antimicrobial Drugs in the Treatment of Respiratory Tract Infections (HAPPY AUDIT)

\section{References}

1. Evertsen J, Baumgardner DJ, Regnery A, Banerjee I. Diagnosis and management of pneumonia and bronchitis in outpatient primary care practices. Prim Care Respir J 2010;19(3):237-41. http://dx.doi.org/10.4104/pcrj.2010.00024

2. Levy ML, Le J, I, Woodhead MA, Macfarlaned JT, Lim WS. Primary care summary of the British Thoracic Society guidelines for the management of community acquired pneumonia in adults: 2009 update. Endorsed by the Royal College of General Practitioners and the Primary Care Respiratory Society UK. Prim Care Respir J 2010;19(1):21-7. http://dx.doi.org/10.4104/pcrj.2010.00014

3. Steurer J, Held U, Spaar A, et al. A decision aid to rule out pneumonia and reduce unnecessary prescriptions of antibiotics in primary care patients with cough and fever. BMC Med 2011;9:56. http://dx.doi.org/10.1186/1741-7015-9-56

4. Bronzwaer SL, Cars O, Buchholz U, et al. A European study on the relationship between antimicrobial use and antimicrobial resistance. Emerg Infect Dis 2002;8(3):278-82. http://dx.doi.org/10.3201/eid0803.010192

5. Magee JT, Pritchard EL, Fitzgerald KA, Dunstan FD, Howard AJ. Antibiotic prescribing and antibiotic resistance in community practice: retrospective study, 1996-8. BMJ 1999;319(7219):1239-40. http://dx.doi.org/10.1136/bmj.319.7219.1239

6. Sande-Bruinsma N, Grundmann $H$, Verloo D, et al. Antimicrobial drug use and resistance in Europe. Emerg Infect Dis 2008;14(11):1722-30. http://dx.doi.org/10.3201/eid1411.070467

7. Bjerrum L, Munck A, Gahrn-Hansen B, et al. Health Alliance for Prudent Antibiotic Prescribing in Patients with Respiratory Tract Infections (HAPPY AUDIT): impact of a non-randomised multifaceted intervention programme. BMC Fam Pract 2011; 12:52. http://dx.doi.org/10.1186/1471-2296-12-52

8. Bjerrum L, Munck A, Gahrn-Hansen B, et al. Health Alliance for Prudent Prescribing, Yield and Use of Antimicrobial Drugs in the Treatment of Respiratory Tract Infections (HAPPY AUDIT). BMC Fam Pract 2010;11:29 http://dx.doi.org/10.1186/1471-2296-11-29

9. Munck AP, Hansen DG, Lindman A, Ovhed I, Forre S, Torsteinsson JB. A Nordic collaboration on medical audit. The APO method for quality development and continuous medical education (CME) in primary health care. Scand J Prim Health Care 1998;16(1):2-6. http://dx.doi.org/10.1080/028134398750003313

10. Altman DG, Bland JM. Interaction revisited: the difference between two estimates. BMJ 2003:326(7382):219. http://dx.doi.org/10.1136/bmj.326.7382.219

11. Diehr P, Wood RW, Bushyhead J, Krueger L, Wolcott B, Tompkins RK. Prediction of pneumonia in outpatients with acute cough--a statistical approach. J Chronic Dis 1984;37(3):215-25. http://dx.doi.org/10.1016/0021-9681(84)90149-8

12. O'Brien WT Sr, Rohweder DA, Lattin GE Jr, et al. Clinical indicators of radiographic findings in patients with suspected community-acquired pneumonia: who needs a chest x-ray? J Am Coll Radiol 2006;3(9):703-6. http://dx.doi.org/10.1016/j.jacr.2006.02.007

13. Baker R, Robertson N, Farooqi A. Audit in general practice: factors influencing participation. BMJ 1995;311(6996):31-4 http://dx.doi.org/10.1136/bmj.311.6996.31

14. Lervy B, Wareham K, Cheung WY. Practice characteristics associated with audit activity: a Medical Audit Advisory Group survey. Br J Gen Pract 1994;44(384):311-14.

15. Hopstaken RM, Muris JW, Knottnerus JA, Kester AD, Rinkens PE, Dinant GJ. Contributions of symptoms, signs, erythrocyte sedimentation rate, and C-reactive protein to a diagnosis of pneumonia in acute lower respiratory tract infection. $\mathrm{Br} J$ Gen Pract 2003;53(490):358-64.

16. Bjerrum L, Munck A, Reutskiy A, et al. Health Alliance for Prudent Prescribing, Yield And Use of Antimicrobial Drugs in the Treatment of Respiratory Tract Infections (HAPPY AUDIT). BMC Fam Pract 2010;11:29 http://dx.doi.org/10.1186/1471-2296-11-29.

17. Holm A, Nexoe J, Bistrup LA, et al. Aetiology and prediction of pneumonia in lower respiratory tract infection in primary care. Br J Gen Pract 2007;57(540):547-54.

18. Woodhead M, Blasi F, Ewig S, et al. Guidelines for the management of adult lower respiratory tract infections--full version. Clin Microbiol Infect 2011;17(Suppl 6):E159. http://dx.doi.org/10.1111\%2Fj.1469-0691.2011.03672.x

19. van Vugt SF, Broekhuizen BD, Lammens $C$, et al. Use of serum $C$ reactive protein and procalcitonin concentrations in addition to symptoms and signs to predict pneumonia in patients presenting to primary care with acute cough: diagnostic study. BMJ 2013;346:f2450. http://dx.doi.org/10.1136/bmj.f2450

20. van Vugt SF, Verheij $T$, de Jong PA, et al. Diagnosing pneumonia in patients with acute cough: clinical judgment compared to chest radiography. Eur Respir J 2013;42(4):1076-82. http://dx.doi.org/10.1183/09031936.00111012

21. van der Meer, $V$, Neven AK, van den Broek PJ, Assendelft WJ. Diagnostic value of $C$ reactive protein in infections of the lower respiratory tract: systematic review. $B M$ 2005;331(7507):26. http://dx.doi.org/10.1136/bmj.38483.478183.EB

22. Gjelstad S, Straand J, Dalen I, Fetveit A, Strom H, Lindbaek M. Do general practitioners' consultation rates influence their prescribing patterns of antibiotics for acute respiratory tract infections? J Antimicrob Chemother 2011;66(10):2425-33. http://dx.doi.org/10.1093/jac/dkr295

23. Akkerman AE, Kuyvenhoven MM, van der Wouden JC, Verheij TJ. Determinants of antibiotic overprescribing in respiratory tract infections in general practice. $J$ Antimicrob Chemother 2005;56(5):930-6. http://dx.doi.org/10.1093/jac/dki283

24. Cals JW, Boumans D, Lardinois RJ, et al. Public beliefs on antibiotics and respiratory tract infections: an internet-based questionnaire study. $\mathrm{Br} J \mathrm{Gen}$ Pract 2007;57(545):942-7. http://dx.doi.org/10.3399/096016407782605027

25. Dosh SA, Hickner JM, Mainous AG, III, Ebell MH. Predictors of antibiotic prescribing for nonspecific upper respiratory infections, acute bronchitis, and acute sinusitis. An UPRNet study. Upper Peninsula Research Network. J Fam Pract 2000;49(5):407-14

26. Bjerrum L, Boada A, Cots JM, et al. Respiratory tract infections in general practice: considerable differences in prescribing habits between general practitioners in Denmark and Spain. Eur J Clin Pharmacol 2004;60(1):23-8. http://dx.doi.org/10.1007\%2Fs00228-003-0706-z

Available online at http://www.thepcrj.org 